This item was submitted to Loughborough's Research Repository by the author.

Items in Figshare are protected by copyright, with all rights reserved, unless otherwise indicated.

\title{
Controlling the assembly of C2-symmetric molecular tectons using a thiocarbamate appended carbocyclic cleft molecule analogous to Tröger's base
}

\section{PLEASE CITE THE PUBLISHED VERSION}

http://dx.doi.org/10.1021/acs.cgd.6b00388

\section{PUBLISHER}

(c) American Chemical Society

\section{VERSION}

AM (Accepted Manuscript)

\section{PUBLISHER STATEMENT}

This work is made available according to the conditions of the Creative Commons Attribution-NonCommercialNoDerivatives 4.0 International (CC BY-NC-ND 4.0) licence. Full details of this licence are available at: https://creativecommons.org/licenses/by-nc-nd/4.0/

\section{LICENCE}

CC BY-NC-ND 4.0

\section{REPOSITORY RECORD}

Slater, Natasha H., Benjamin R. Buckley, Mark R.J. Elsegood, Simon J. Teat, and Marc C. Kimber. 2019. "Controlling the Assembly of C2-symmetric Molecular Tectons Using a Thiocarbamate Appended Carbocyclic Cleft Molecule Analogous to Tröger's Base”. figshare. https://hdl.handle.net/2134/21641. 


\section{Controlling the assembly of C2-symmetric}

molecular tectons using a thiocarbamate appended carbocyclic cleft molecule analogous to Tröger's base Natasha H. Slater, ${ }^{a}$ Benjamin R. Buckley, ${ }^{a}$ Mark R. J. Elsegood, ${ }^{a^{*}}$ Simon J. Teat ${ }^{b}$ and Marc C. Kimber ${ }^{a^{*}}$

${ }^{a}$ Department of Chemistry, Loughborough University, LE11 3TU, UK.

${ }^{b}$ ALS, Berkeley Laboratory, 1 Cyclotron Road, MS2-400, Berkeley, California, 94720, USA

\section{ABSTRACT}

By way of appending the $\mathrm{C}_{2}$-symmetric carbocyclic cleft diol with thiocarbamates with varying substituents, significant control of the hydrogen bonded network can be achieved. Smaller alkyl substituents lead to the formation of stacked columns of components with the apex of one molecule suitably aligned in the cleft of a second. Aryl substituents however, lead to the formation of ribbons via an H-bonding network. Additionally, the packing of these ribbons into networks is considerably different between the enantiopure and racemic clefts, with the latter giving rise to channels within the crystal structure. 


\section{INTRODUCTION}

The carbocyclic diol cleft molecule $\mathbf{1}^{1-3}$ has become a surrogate for Tröger's base (2) in catalysis, ${ }^{4}$ supramolecular chemistry ${ }^{5-7}$ and chiral recognition (figure 1 ). ${ }^{8-11}$ It is analogous to Tröger's base as it contains a $\mathrm{C}_{2}$-symmetric axis, a chiral cavity with a defined geometry and a rigid, predictable structure. This give $\mathbf{1}$ a predictable $\mathrm{V}$-shape, whose angle $(\theta)$ can vary between $83.4^{\circ}$ to $104.3^{\circ}$ depending on the substitution on the aromatic ring. ${ }^{12,13}$ The advantages of 1 over Tröger's base lie in the diol, with the two hydroxyl groups being pointed into the interior of the cleft giving the ability, via hydrogen bonding, to orientate and organize substrates into this uniquely chiral cavity. We have previously emphasized the practicality of $\mathbf{1}$ by appending the hydroxyl groups with pyridyl functionality, as well as highlighting the self-assembly of these pyridyl adducts with phenylboronic acid to yield bisboroxine substrates, with the 4-pyridyl analogue being fully characterized by single crystal X-ray analysis emphasizing the chiral space. ${ }^{14,15}$

Figure 1. The $\mathrm{C}_{2}$-centrosymmetric chiral cleft diol 1.

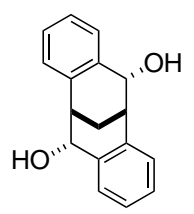

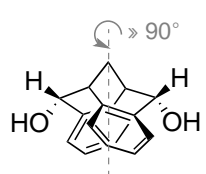

Diol 1

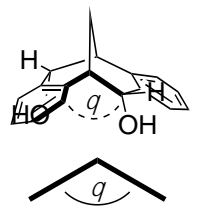

$83.4-104.3^{\circ}$

The capacity to be able to confidently predict crystal packing to facilitate the design of new solids with sought after physical properties has been central to the evolution of crystal engineering. ${ }^{16-18}$ Furthermore, the ability to control secondary and tertiary structure within crystal packing has enormous potential in the development of new functional materials and devices. Molecular tectonics ${ }^{19-22}$ is the analysis of molecular crystals and their subsequent formation of networks, and as a consequence the tecton is defined as a construction unit with 
defined structural and energetic attributes that can control assembly via programmed molecular recognition processes. Consequently, the identification of new 3-dimensional chiral molecules, or tectons, with rigid, predictable structures opens further prospects in expanding the scope of crystal engineering.

Akin to Troger's base (2), ${ }^{23,24}$ diol $\mathbf{1}$ can pack, in the solid state, in four possible forms M1, M2, M3 and M4, all of which are primarily driven by weak van der Waals, and $\pi-\pi$ interactions (figure 2). ${ }^{25}$

Figure 2. Control of crystal packing in chiral cleft diol 1.
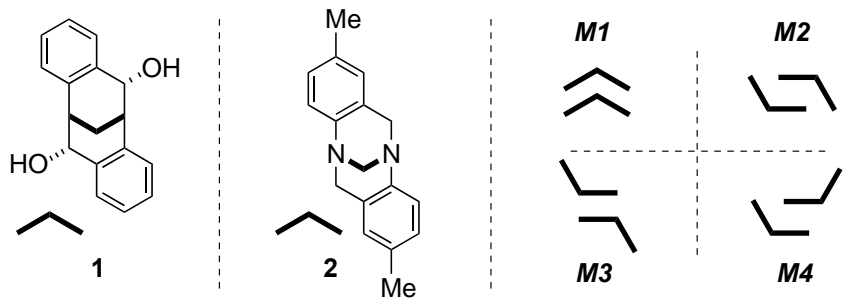

Conversely, thiocarbamates (3) like amides, form networks based on stronger hydrogen bonding, which is, in part, controlled by their configuration, with the cisoid form 3a leading to synthon $\mathbf{4}$, and the transoid form $\mathbf{3 b}$ leading to synthon $\mathbf{5}$ (scheme 1). ${ }^{26,27}$

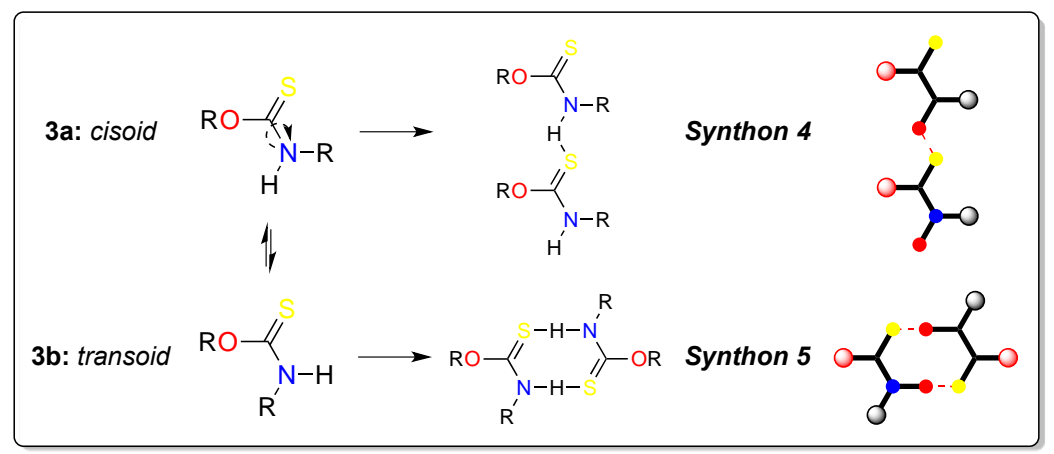

Scheme 1. Control of crystal packing in thiocarbamate 3 . 
In an effort to regulate the crystal packing of chiral cleft $\mathbf{1}$, we envisaged appending the diol with a variety of thiocarbamates (alkyl and aryl, scheme 2, 6). The crystal packing of these derivatives would then be primarily defined by the orientation of the thiocarbamate (cisoid and/or transoid) that is accurately described by $\mathbf{6 a} \leftrightarrow \mathbf{6 b} \leftrightarrow \mathbf{6 c}$. This would serve two purposes: (a) to allow the confident prediction of the crystal packing of $\mathbf{6}$, therefore demonstrating this scaffold as a potential tecton; (b) to demonstrate that novel crystalline solids with predictable chiral environments can be formed from analogues of $\mathbf{1}$.
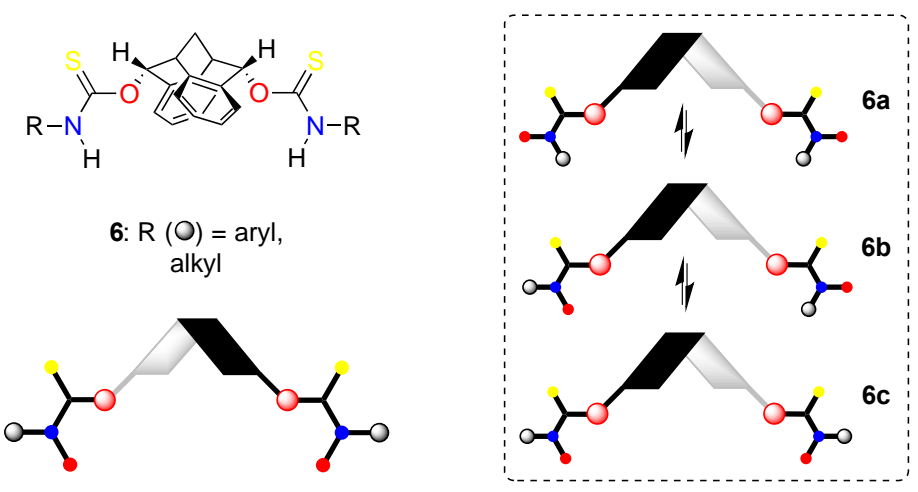

Scheme 2. Targeted thiocarbamates.

\section{RESULTS AND DISCUSSION}

\section{Preparation of thiocarbamate appended clefts}

The synthesis of the thiocarbamate cleft derivatives began with obtaining multi-gram quantities of the parent cleft diol $\mathbf{1}$, and this was achieved as reported previously (scheme 3 ). ${ }^{2}$ This racemic diol could then be converted to the bis-thiocarbamate by treatment with $\mathrm{NaH}$ and excess isothiocyanate. This was accomplished with phenyl, tolyl, 3,5ditrifluromethylphenyl, methyl, and butyl isothiocyanates giving the desired compounds $( \pm)-$ 10a-e in moderate to good yields. In addition to the racemic thiocarbamates, enantiopure tolyl 
thiocarbamate was also prepared (scheme 3). This was achieved by synthesizing the enantiopure di-acid $(+)-8$ via resolution of its racemate with quinine. This enantiopure diacid was then converted to the thiocarbamate, delivering enantiopure $(+)-\mathbf{1 0 b}$.

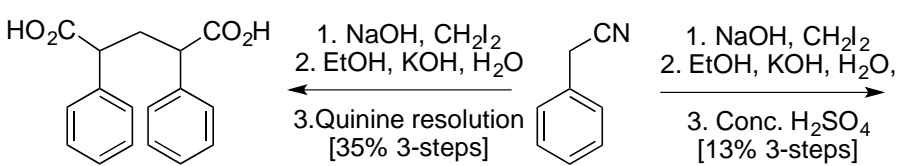

$(+)-8$
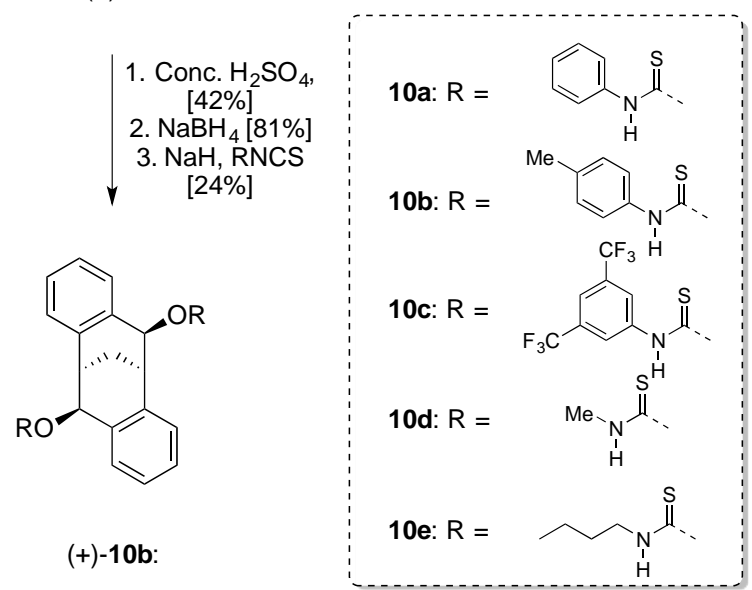

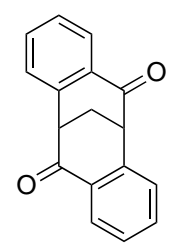

$( \pm)-9$

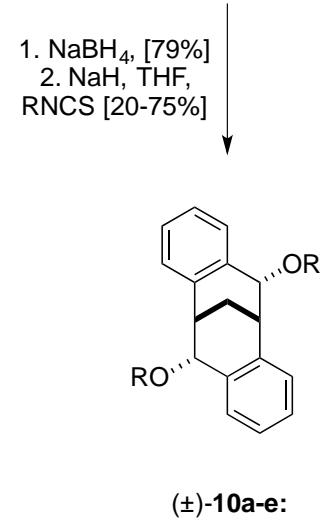

$( \pm)-10 a-e:$

Scheme 3. Preparation of thiocarbamates $( \pm)-\mathbf{1 0 a}-\mathbf{e}$ and $(+)-\mathbf{1 0 b}$.

\section{X-ray crystallographic analysis}

Single crystal X-ray analysis was performed on phenyl $( \pm)-\mathbf{1 0 a}$, tolyl $( \pm)-\mathbf{1 0 b}, 3,5-$ ditrifluromethylphenyl ( \pm )-10c, methyl $( \pm)-\mathbf{1 0 d}$, and butyl $( \pm)-\mathbf{1 0 e}$ thiocarbamates. Additionally, single crystal $\mathrm{X}$-analysis was also performed on the enantiopure tolyl $(+)-\mathbf{1 0 b}$ analogue as a comparison with its racemic analogue. Crystal data, H-bond geometry, and $50 \%$ ORTEP plots are presented in the SI, and crystallographic procedures are described in the experimental section. ${ }^{28}$

The crystal structure of the racemic phenyl-amino-thiocarbamate cleft $( \pm)-10 a$ illustrates the rigid cleft framework and the position of the two appending phenyl-amino-thiocarbamate 
units that are orientated towards the interior of the cleft. ${ }^{28}$ Interestingly the sulfur and thiocarbamate $\mathrm{N}-\mathrm{H}$ groups are pointing outwards away from the cleft cavity such that only the aromatic phenyl groups are directed inwards towards the cleft. Molecules of $( \pm)-\mathbf{1 0 a}$ were shown to interact with each other according to the packing plot shown in figure 3(a). Thus, molecules of $( \pm)-10 a$ are linked together in a $1 \mathrm{D}$ polymeric $\mathrm{H}$-bonded chain with aminothiocarbamate groups forming pairs of $\mathrm{R}_{2}^{2}(8)$, centro-symmetric $\mathrm{N}-\mathrm{H} \cdots \mathrm{S}$ H-bond interactions to neighboring molecules. ${ }^{26,27,29}$

Figure 3. X-ray analysis and the H-bonded chain of $( \pm)-\mathbf{1 0 a},(+)-\mathbf{1 0 b}$ and $( \pm)-\mathbf{1 0 b}$, respectively.

(a) ( \pm -10a

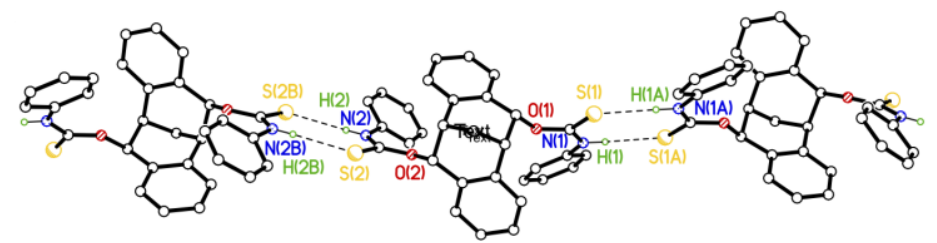

(b) $(+)-10 b$

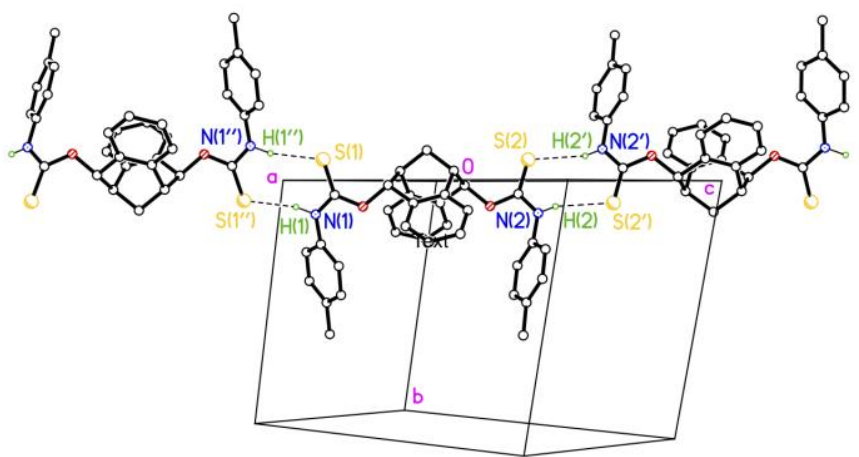




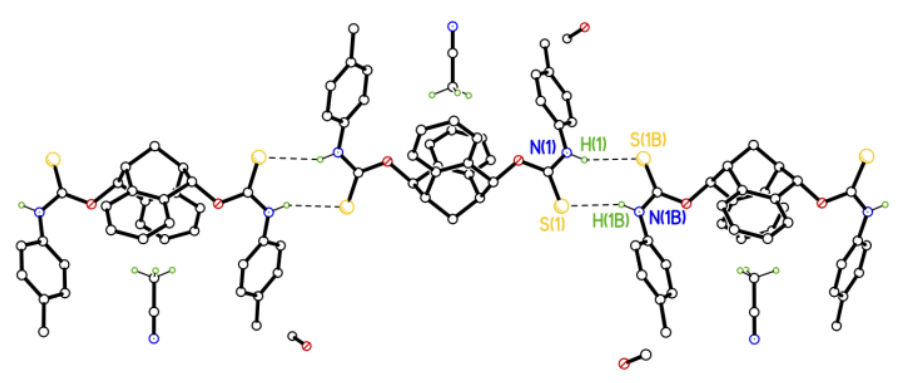

The X-Ray crystal structure ${ }^{30}$ of the $(+)$-enantiomer of the $p$-tolyl-amino-thiocarbamate cleft $(+)-10 b$, shows that the substituted amino-thiocarbamate groups are also directed into the cavity of the cleft bicycle with the thiocarbamate sulfur and $\mathrm{N}-\mathrm{H}$ groups pointing outwards away from the center of the cavity. ${ }^{28}$ Molecules of $(+)-\mathbf{1 0 b}$ were bound to each other by a very similar H-bonding network as displayed in the crystal structure of ( \pm )-10a. Thus molecules are linked together via pairs of $\mathrm{R}_{2}^{2}(8)$, centro-symmetric $\mathrm{N}-\mathrm{H} \cdots \mathrm{S}$ H-bonds forming chains of molecules (figure 3(b)). ${ }^{31}$ Essentially the molecular structure of $( \pm)$-10b is exactly the same as the $(+)$-enantiomer with complexing $p$-tolyl-amino-thiocarbamate groups pointing into the cavity of the cleft bicycle and both the $\mathrm{N}-\mathrm{H}$ and sulfur groups of the appending amino-thiocarbamate groups pointing away from the interior of the cavity. ${ }^{30}$ Like in $(+)-\mathbf{1 0 b}$, this arrangement of functional groups allowed molecules to form chains linked by pairs of $\mathrm{R}^{2}{ }_{2}(8)$, centro-symmetric $\mathrm{N}-\mathrm{H} \cdots \mathrm{S}$ H-bonds (figure $\left.3(\mathrm{c})\right)^{32}$

However, unlike the crystal structure of $(+)-\mathbf{1 0 b}$, which was found to contain crystallographically independent molecules with no solvent of crystallization, the crystal structure of the racemic compound $( \pm)-\mathbf{1 0 b}$ contained solvate molecules of methanol which lie disordered over a two-fold axis exo- to the cleft molecules. In addition, an acetonitrile solvate molecule bound via a pair of $\mathrm{C}-\mathrm{H} \cdots \pi$ interactions resides in the cleft cavity (figures $3 c$ and $4 b)$. Interestingly, because the cleft cavity is occupied with solvent molecules bound 
to the cleft by moderate $\mathrm{C}-\mathrm{H} \cdots \pi$ interactions, neighboring $\mathrm{H}$-bonded chains made up of molecules of $( \pm)-\mathbf{1 0 b}$ are unable to interact as they did in $(+)-\mathbf{1 0 b}$ where the terminal $p$-tolyl group from one chain penetrates into the cavity of the molecule in the next chain forming an 'above / below' type packing pattern (type M2 figure 4(a)). Instead chains of H-bonded molecules arrange into groups of six molecules which interact to form rings with the internal clefts filled with acetonitrile solvate molecules (figure 4(b)).

Figure 4. Comparison of the packing pattern of enantiopure and racemic $\mathbf{1 0 b}$, both of which illustrate M2-type pack of the $\mathrm{C}_{2}$-centrosymmetric cleft.

(a) $(+)-10 b$

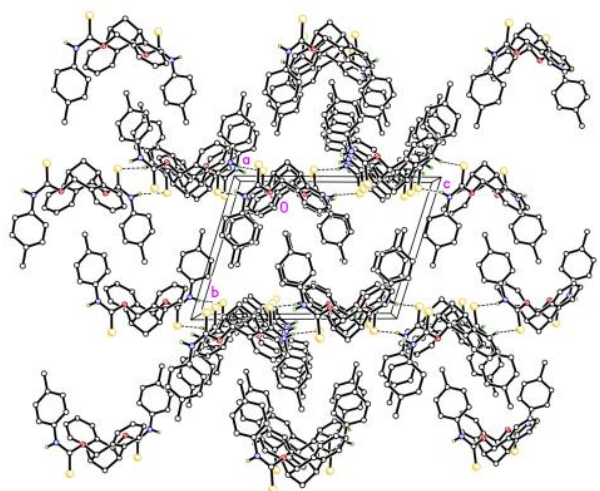

(b) $( \pm)-10 b$

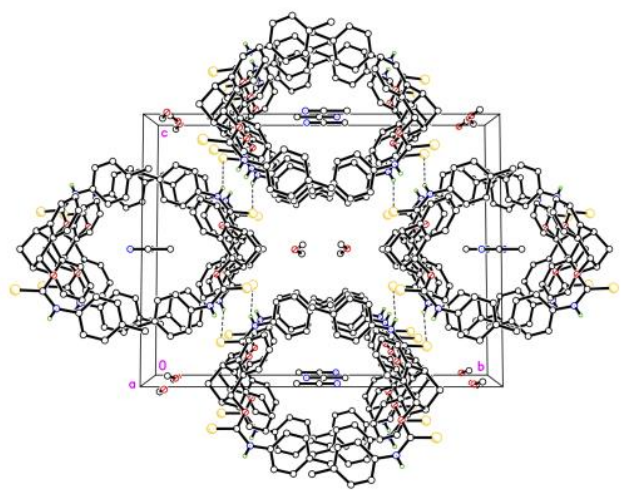

In the crystal structure of $( \pm)-\mathbf{1 0 c}$, the fluorine atoms which make up the $\mathrm{CF}_{3}$ groups were modeled as split over two sets of positions with one of the $\mathrm{C}_{6} \mathrm{H}_{3} \mathrm{CF}_{3}$ groups ${ }^{28}$ showing the potential to be more disordered than the others. ${ }^{33}$ Like the other $N$-aryl functionalized aminothiocarbamate clefts the $\mathrm{Ph}\left(\mathrm{CF}_{3}\right)_{2}$ substituted amino-thiocarbamate groups in $( \pm)-\mathbf{1 0 c}$ are directed into the cleft cavity with the thiocarbamate sulfur and $\mathrm{N}-\mathrm{H}$ groups directed away from the interior of the cleft. It would appear from X-Ray packing plots that the bulky pendant fluorinated aromatic groups block the cleft cavity, preventing any interactions between the $\pi$-systems of neighboring cleft molecules. As a result, the only significant non- 
covalent interactions observed are $\mathrm{H}$-bonds in $( \pm)-10 c$ between the thiocarbamate $\mathrm{N}-\mathrm{H}$ groups and the sulfur atom of a neighboring molecule resulting in a 2-dimentional H-bonded sheet via one $\mathrm{R}_{2}^{2}(8)$, centro-symmetric motif and several chain linkages (figure 5).

Figure 5. X-ray H-bonding analysis of $( \pm)-10 c$. The 3,5-ditrifluoromethylphenyl groups have been omitted for clarity.

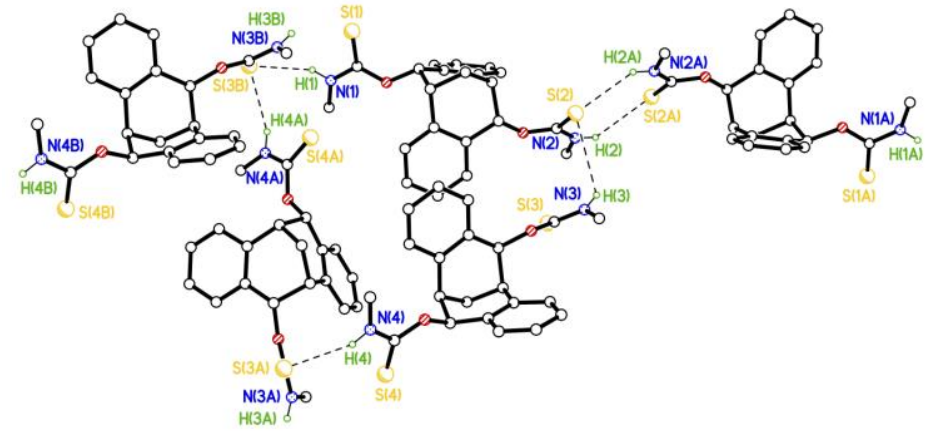

The length of the H-bonds between the sulfur and $\mathrm{N}-\mathrm{H}$ groups ${ }^{34}$ are very similar to those observed in $(+)-\mathbf{1 0 b}$ and $( \pm)-\mathbf{1 0 b}$, however the overall packing pattern displayed in this structure is considerably more complex due to the fluoroaryl groups.

As in the $p$-tolyl, phenyl and fluoroaryl substituted amino-thiocarbamate groups the appending methyl-thiocarbamate groups of $( \pm)-\mathbf{1 0 d} \mathbf{d}^{30}$ are directed into the cavity of the cleft. ${ }^{28}$ However, unlike the $N$-aryl substituted thiocarbamate clefts mentioned previously, the thiocarbamate $\mathrm{N}-\mathrm{H}$ groups in $( \pm)-\mathbf{1 0 d}$ are shown to be directed into the cavity of the cleft; presumably the less bulky methyl groups facilitate this orientation. This removes the ability of the thiocarbamate $\mathrm{N}-\mathrm{H}$ groups to form centro-symmetric $\mathrm{H}$-bonds with neighboring clefts, as demonstrated by the clefts $(+)-\mathbf{1 0 b}$ and $( \pm)-\mathbf{1 0 b}$ (figures 3 and 4 ), which appears to influence the way in which molecules of $( \pm)-\mathbf{1 0 d}$ interact with each other. The packing pattern displayed by $( \pm$-10d showed that molecules are linked via $\mathrm{N}-\mathrm{H} \cdots \mathrm{S}$ H-bonds into 
chains / ladders, thus the apex of one molecule is accommodated in the cleft of the next to form columns of apex-to-base stacked molecules, like a stack of party hats (type M1). ${ }^{35}$ The two hydrogens in the $\mathrm{CH}_{2}$ at the bridgehead of the cleft at $\mathrm{C}(9) ; \mathrm{C}(30)$ and $\mathrm{C}(51)$ (figure 6(a)) make up pairs of $\mathrm{C}-\mathrm{H}^{\cdots} \cdot \pi$ interactions with the cleft of the molecule 'above'. ${ }^{36}$ In addition to this molecular stacking pattern, this cleft presents a highly unusual cooperative packing system, where each group of three molecules is H-bonded to the next group of three molecules but with a $180^{\circ}$ rotation between one group and the next. ${ }^{37}$

Weakly diffracting crystals of $( \pm)-10 e$ were obtained and analyzed using synchrotron radiation. ${ }^{28,30}$ There were difficulties in uniquely identifying the space group which are described in the experimental section. Despite these problems the identification of the compound and the nature of the stacking was clearly established (figure 6(b)). The stacking adopted is the same M1 motif adopted by the methyl analog ( \pm )-10d.

Figure 6. X-ray analysis of $( \pm)-10 d$ and $( \pm)-10 e$, respectively illustrating the H-bonded ladder network.

(a) $( \pm)-10 d$

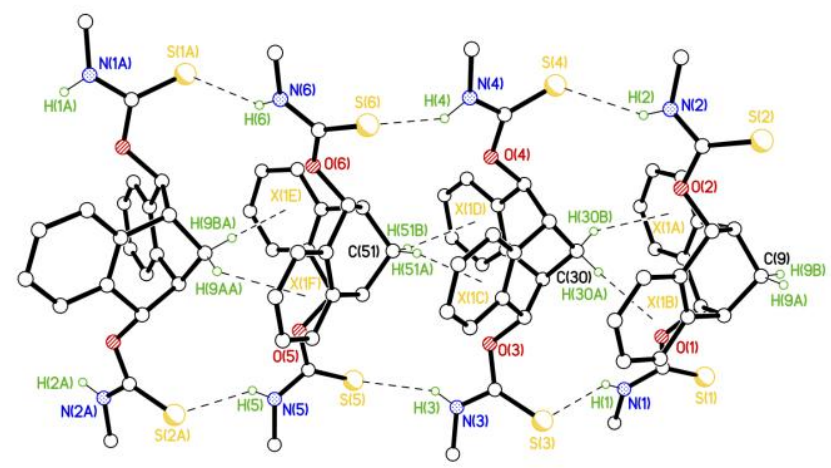

(b) ( \pm -10e 


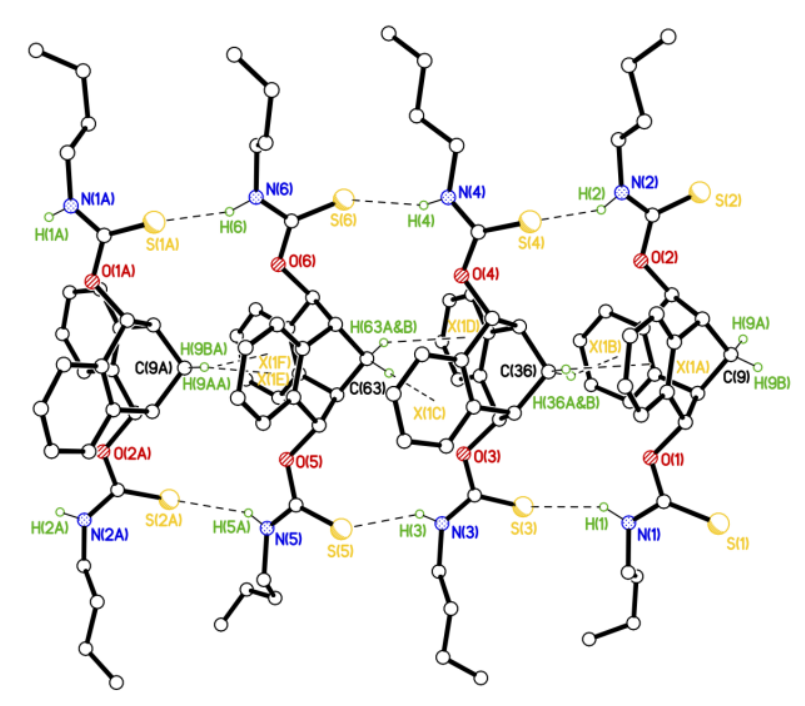

From the X-ray data it is clear that the size of the $\mathrm{R}$ group on the thiocarbamate effects the orientation and packing of the cleft. In the case of the R being alkyl (methyl or ${ }^{n}$ butyl) both the thiocarbamates take on the cisoid conformation (scheme 4, 6a) and this promotes synthon 4 giving ( \pm )-11d and $( \pm)-11 e$, respectively. This is further reinforced by weak, non-bonding interactions forming columns of two or more components with the apex of one molecule suitably aligned in the cleft of a second, and can be defined as M1 type packing.

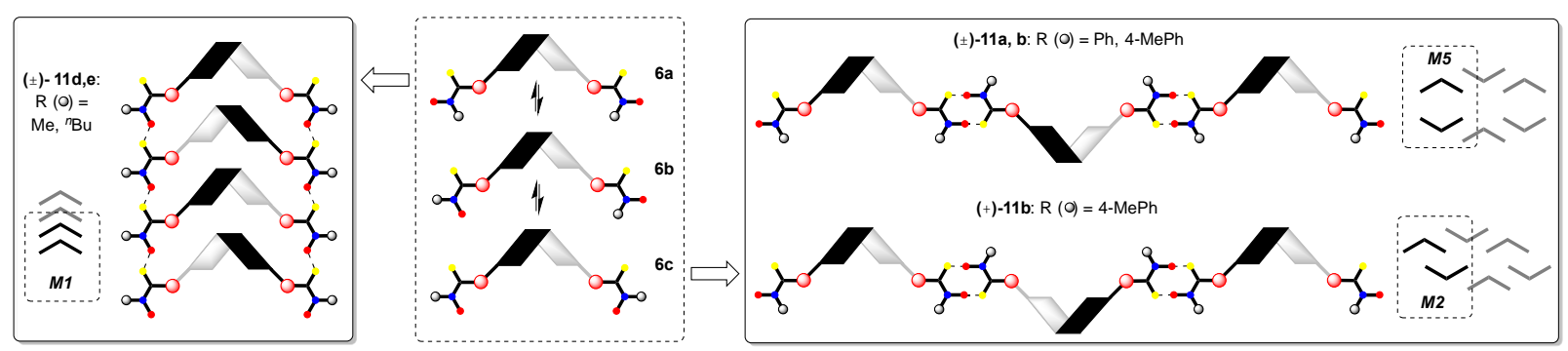

Scheme 4. The role of the thiocarbamate in determining crystal structure and the H-bonded network.

However, when $\mathrm{R}$ is an aryl group the preferred conformation of the thiocarbamate is transoid (6c) which promotes synthon $\mathbf{5}$ giving ribbons of clefts within the crystal structures $( \pm)-\mathbf{1 1 a}, \mathbf{b}$ and $(+)-\mathbf{1 1 b}$. The packing of these ribbons in the enantiopure clefts $(+)-\mathbf{1 1} \mathbf{b}$ is then 
controlled by the insertion of an aryl group of one cleft into the cleft of another via endo-face to endo-face interactions, and can be defined as $\mathbf{M} 2$ type packing. In contrast, in the racemic series $( \pm)-\mathbf{1 1 a}, \mathbf{b}$ the packing of these ribbons gives rise to a new motif M5, which promotes the formation of rings with the internal clefts filled with acetonitrile solvate molecules. Clearly this latter network provides the opportunity to form other host:guest complexes using these channels. Finally, the $3,5-\mathrm{CF}_{3} \mathrm{Ph}$ thiocarbamate $( \pm)-\mathbf{1 0 c}$, which contains bulky pendant fluorinated aromatic groups that block the cleft cavity, presumably forms networks using the cisoid (6a), transoid (6c) or mixtures of both forms (6b), giving a disordered H-bonded network.

\section{CONCLUSIONS}

Through using a combination of a novel chiral cleft molecule and thiocarbamates we have demonstrated that we can control the crystal packing by simple variation of the size of the substituent on the thiocarbamate. This has been achieved due to the tendency of the $\mathrm{C}_{2^{-}}$ symmetric cleft to form molecule associations within the solid state described as M1-M4, and thiocarbamates to form synthons via their cisoid and transoid conformers. Smaller substituents lead to H-bonding in the thiocarbamate in its cisoid form, and this is further strengthened by type M1 interactions. Larger substituents such as phenyl and tolyl lead to Hbonding ribbon type networks via the transoid form of the thiocarbamate. However, we have demonstrated that the packing of these ribbons differs significant between the racemic and enantiopure clefts, with the racemic series giving rise to channels within the crystal structure, via a new type of interaction M5. Moreover, the crystal structure of $( \pm)-\mathbf{1 0 b}$ provided evidence of the ability of these novel amino-thiocarbamate clefts to bind guest molecules with complementary size and binding features. Interestingly, binding within the cleft cavity was facilitated by $\mathrm{C}-\mathrm{H} \cdots \pi \mathrm{H}$-bond interactions originating from the core carbocyclic cleft 
framework, and not by $\mathrm{H}$-bonds involving the thiocarbamate groups. Given that cleft $\mathbf{1}$ is $\mathrm{C}_{2}$ symmetric, this simple but effective control of crystallization within the solid state has significant potential to be expanded upon using other hydrogen bond synthons.

\section{EXPERIMENTAL}

General Procedure for the Preparation of Amino-thiocarbamate Clefts. Sodium hydride (60\% mineral oil, $4.0 \mathrm{mmol})$ was washed with hexane $(3 \times 10 \mathrm{~mL})$ and dried under vacuum, THF $(10 \mathrm{~mL})$ was added and the suspension was cooled to $0^{\circ} \mathrm{C}$. Racemic $( \pm)-\mathbf{1}$ or $(+)-\mathbf{1}(1.0$ mmol) was dissolved in THF (5 mL) and added to the sodium hydride suspension via a cannula under nitrogen and the reaction was stirred at $0^{\circ} \mathrm{C}$ for $25 \mathrm{~min}$. After this time a solution of substituted isothiocyanate $(3.0 \mathrm{mmol})$ in THF $(5 \mathrm{~mL})$ was added dropwise to the reaction mixture. The solution was allowed to warm to room temperature and then stirred for a further $18 \mathrm{~h}$; reactions were monitored by TLC. After this time the reaction was quenched by the careful addition of water $(20 \mathrm{~mL})$ and extracted with dichloromethane $(3 \mathrm{x} 25 \mathrm{~mL})$. The combined organic layers were washed with brine $(25 \mathrm{~mL})$, dried over $\mathrm{MgSO}_{4}$, filtered and concentrated to dryness in vacuo. The crude compound was purified by silica column chromatography.

( \pm -2,8-Dibenzobicyclo $[b, f][3.3 .1]$ nona-5a, 6a-dien-6,12-phenyl amino thiocarbamate (士)-10a. (0.2 g, 57 \%), fine white solid; Mp 111.6 - $114.7{ }^{\circ} \mathrm{C} ;{ }^{1} \mathrm{H}$ NMR $\left(400 \mathrm{MHz}, \mathrm{CDCl}_{3}\right): \delta$ $7.74-7.00(\mathrm{~m}, 20 \mathrm{H}), 3.91-3.88(\mathrm{~m}, 2 \mathrm{H}), 2.60-2.58(\mathrm{~m}, 2 \mathrm{H}) ;{ }^{13} \mathrm{C}$ NMR $(100 \mathrm{MHz}$ $\left.\mathrm{CDCl}_{3}\right): \delta 188.41,136.86,136.65,134.61,133.96,130.67,130.48,129.04,127.66,127.47$,

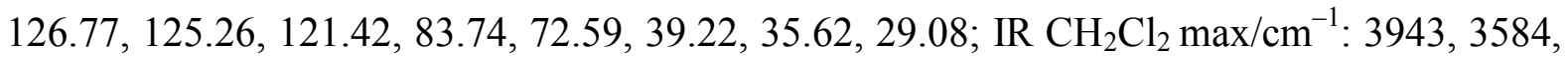
$3361(\mathrm{~N}-\mathrm{H})$, 3054, 2986 (aromatics), 2305, 1526, 1265, 1160, 1034, 743, 705; HRMS m/z found $545.1327 \mathrm{C}_{31} \mathrm{H}_{26} \mathrm{O}_{2} \mathrm{~N}_{2} \mathrm{~S}_{2}\left(\mathrm{M}^{+} \mathrm{Na}\right)$ expected $545.1328\left(\mathrm{M}^{+} \mathrm{Na}\right)$; Elemental Analysis found C 71.06; $\mathrm{H} 4.98 ; \mathrm{N} 5.41 \% \mathrm{C}_{31} \mathrm{H}_{26} \mathrm{~N}_{2} \mathrm{O}_{2} \mathrm{~S}_{2}$ requires C 71.24; $\mathrm{H} 5.01 ; \mathrm{N} 5.36 \%$. 
$( \pm)$-2,8-Dibenzobicyclo $[b, f][3.3 .1]$ nona-5a, 6a-dien-6,12-p-tolyl amino thiocarbamate ( \pm -10b. (0.4 g, 70 \%) fine white solid; $\mathrm{Mp} 209.9-211.2{ }^{\circ} \mathrm{C} ;{ }^{1} \mathrm{H} \mathrm{NMR}\left(400 \mathrm{MHz}, \mathrm{CDCl}_{3}\right): \delta$ $7.58(\mathrm{~d}, J=8.4 \mathrm{~Hz}, 2 \mathrm{H}), 7.29-7.15(\mathrm{~m}, 7 \mathrm{H}), 7.09(\mathrm{~d}, J=7.2 \mathrm{~Hz}, 2 \mathrm{H}), 7.04-6.84(\mathrm{~m}, 7 \mathrm{H})$, $3.89(\mathrm{~m}, 2 \mathrm{H}), 2.58(\mathrm{~m}, 2 \mathrm{H}), 2.41(\mathrm{~s}, 3 \mathrm{H}), 2.28(\mathrm{~s}, 3 \mathrm{H}) ;{ }^{13} \mathrm{C} \mathrm{NMR}\left(100 \mathrm{MHz}, \mathrm{CDCl}_{3}\right): \delta$ $188.30,136.32,135.36,134.92,134.83,133.85,131.05,129.72,129.54,127.39,127.11$, $126.55,123.59,121.47,83.37,79.45,46.00,35.36,20.93 ; \mathrm{IR} \mathrm{CH}_{2} \mathrm{Cl}_{2} \max / \mathrm{cm}^{-1}: 3944$ (s, NH), 3689 (s, N-H), 2986 (aromatics), 2305, 1520, 1265, 739, 704; HRMS $\mathrm{m} / \mathrm{z}$ found $573.1639 \mathrm{C}_{33} \mathrm{H}_{30} \mathrm{O}_{2} \mathrm{~N}_{2} \mathrm{~S}_{2}\left(\mathrm{M}^{+} \mathrm{Na}\right)$ expected $573.1641\left(\mathrm{M}^{+} \mathrm{Na}\right)$; Elemental analysis found $\mathrm{C}$ 71.55; H 5.46; N $5.13 \% ; \mathrm{C}_{33} \mathrm{H}_{30} \mathrm{~N}_{2} \mathrm{O}_{2} \mathrm{~S}_{2}$ requires C 71.97; H 5.49; S 5.09 \%.

$(+)-2,8-D i b e n z o b i c y c l o ~[b, f][3.3 .1]$ nona-5a, 6a-dien-6,12-p-tolyl amino thiocarbamate (+)-10b $(0.26 \mathrm{~g}, 24 \%)$, fine white solid; Mp $116.2-124.7{ }^{\circ} \mathrm{C} ;[\alpha]_{\mathrm{D}}{ }^{21}+174.3\left(c 1.0, \mathrm{CHCl}_{3}\right)$; ${ }^{1} \mathrm{H}$ NMR (400 MHz, $\left.\mathrm{CDCl}_{3}\right): \delta 7.47(\mathrm{~d}, J=7.6 \mathrm{~Hz}, 2 \mathrm{H}), 7.17-7.08(\mathrm{~m}, 7 \mathrm{H}), 6.95(\mathrm{~d}, J=5.2$ $\mathrm{Hz}, 2 \mathrm{H}), 6.89-6.75(\mathrm{~m}, 7 \mathrm{H}), 3.79(\mathrm{~m}, 2 \mathrm{H}), 2.46(\mathrm{~m}, 2 \mathrm{H}), 2.30(\mathrm{~s}, 3 \mathrm{H}), 2.14(\mathrm{~s}, 3 \mathrm{H}) ;{ }^{13} \mathrm{C}$ NMR (100 MHz, $\left.\mathrm{CDCl}_{3}\right): \delta 188.21,136.36,134.84,134.30,131.08,129.61,129.54,127.14$, 126.56, 123.63, 121.52, 83.34, 79.44, 35.42, 28.82, 20.99; IR $\mathrm{CH}_{2} \mathrm{Cl}_{2} \max / \mathrm{cm}^{-1}: 3944,3054$ (N-H), 2986 (aromatics), 2305, 1522, 1265, 1171, 1034, 739, 704; HRMS m/z found $573.1642 \mathrm{C}_{33} \mathrm{H}_{30} \mathrm{O}_{2} \mathrm{~N}_{2} \mathrm{~S}_{2}\left(\mathrm{M}^{+} \mathrm{Na}\right)$ expected $573.1641\left(\mathrm{M}^{+} \mathrm{Na}\right)$; Elemental analysis found $\mathrm{C}$ 71.79; H 5.57; N $5.16 \% ; \mathrm{C}_{33} \mathrm{H}_{30} \mathrm{~N}_{2} \mathrm{O}_{2} \mathrm{~S}_{2}$ requires C 71.97; H 5.49; N 5.09 \%.

( \pm -2,8-Dibenzobicyclo $[b, f]$ [3.3.1]nona-5a, 6a-dien-6,12-bis-3,5- bis (trifluoromethyl) phenyl amino thiocarbamate $( \pm)-10 c .(0.70 \mathrm{~g}, 44 \%)$, off-white solid; Mp $120.1-127.4{ }^{\circ} \mathrm{C}$; ${ }^{1} \mathrm{H}$ NMR $\left(400 \mathrm{MHz}, \mathrm{CDCl}_{3}\right): \delta 8.00-6.20(\mathrm{~m}, 14 \mathrm{H}), 3.85(\mathrm{~s}, 2 \mathrm{H}), 1.44\left(\mathrm{~s}, 2 \mathrm{H} ;{ }^{13} \mathrm{C} \mathrm{NMR}\right.$ $\left(100 \mathrm{MHz}, \mathrm{CDCl}_{3}\right): \delta 194.42,140.05,134.52,128.85,138.83,128.79,128.30,48.82,32.33$; IR $\mathrm{CH}_{2} \mathrm{Cl}_{2} \mathrm{max} / \mathrm{cm}^{-1}$ : 3204, $3055(\mathrm{~N}-\mathrm{H}), 2987$ (aromatics), 2306, 1551, 1139, 1265, 1031, 738, 703; HRMS $m / z$ found 817.0777 $\mathrm{C}_{35} \mathrm{H}_{22} \mathrm{O}_{2} \mathrm{~N}_{2} \mathrm{~S}_{2} \mathrm{~F}_{12}\left(\mathrm{M}^{+} \mathrm{Na}\right)$ expected $817.0823\left(\mathrm{M}^{+} \mathrm{Na}\right)$; 
Elemental analysis found $\mathrm{C} 52.34 ; \mathrm{H} 2.77 ; \mathrm{N} 3.72 \% \mathrm{C}_{35} \mathrm{H}_{22} \mathrm{~F}_{12} \mathrm{~N}_{2} \mathrm{O}_{2} \mathrm{~S}_{2}$ requires $\mathrm{C} 52.90 ; \mathrm{H}$ $2.79 ;$ N $3.53 \%$.

$( \pm)$-2,8-Dibenzobicyclo $[b, f][3.3 .1]$ nona-5a, 6a-dien-6,12-methyl amino thiocarbamate (土)-10d. (0.60 g, $75 \%$ ), colorless solid; Mp 212.1 - 218.2 ${ }^{\circ} \mathrm{C} ;{ }^{1} \mathrm{H}$ NMR (400 MHz, $\left.\mathrm{CDCl}_{3}\right): \delta$ $7.12-7.04(\mathrm{~m}, 8 \mathrm{H}), 6.79(\mathrm{dd}, J=6.8 \mathrm{~Hz}, 1 \mathrm{H}), 6.35(\mathrm{dd}, J=6.0 \mathrm{~Hz}, 1 \mathrm{H}), 3.74(\mathrm{~m}, 1 \mathrm{H}), 3.66$ (m, 1H), $3.13(\mathrm{t}, J=5.2 \mathrm{~Hz}, 6 \mathrm{H}) 2.64(\mathrm{~d}, J=5.2 \mathrm{~Hz}, 1 \mathrm{H}), 2.53(\mathrm{~d}, J=5.2 \mathrm{~Hz}, 1 \mathrm{H}), 1.97(\mathrm{~m}$, $2 \mathrm{H}) ;{ }^{13} \mathrm{C}$ NMR $\left(100 \mathrm{MHz}, \mathrm{CDCl}_{3}\right): \delta 194.190 .09,135.52,135.43,135.26,134.88,130.98$, 127.36, 127.31, 127.20, 126.99, 126.81, 126.77, 126.71; IR $\mathrm{CH}_{2} \mathrm{Cl}_{2} \max / \mathrm{cm}^{-1}: 3399(\mathrm{~N}-\mathrm{H})$, 3052 (aromatics), 1528, 1265, 1068, 737, 703; HRMS $m / z$ found $421.1013 \mathrm{C}_{21} \mathrm{H}_{22} \mathrm{O}_{2} \mathrm{~N}_{2} \mathrm{~S}_{2}\left(\mathrm{M}^{+}\right.$ $\mathrm{Na}$ ) expected $421.1015\left(\mathrm{M}^{+} \mathrm{Na}\right)$; Elemental analysis found $\mathrm{C} 63.07 ; \mathrm{H} 5.58$; N $6.99 \%$ $\mathrm{C}_{21} \mathrm{H}_{22} \mathrm{~N}_{2} \mathrm{O}_{2} \mathrm{~S}_{2}$ requires C 63.29; H 5.56; N $7.03 \%$.

( \pm -2,8-Dibenzobicyclo $[b, f][3.3 .1]$ nona-5a, 6a-dien-butyl amino thiocarbamate $( \pm)-10 \mathrm{e}$. (0.19 g, $20 \%$ ), colorless solid; Mp $213.3-214.4{ }^{\circ} \mathrm{C} ;{ }^{1} \mathrm{H}$ NMR (400 MHz, $\left.\mathrm{CDCl}_{3}\right): \delta 7.46-$ $6.70(\mathrm{~m}, 12 \mathrm{H}), 5.01(\mathrm{~m}, 2 \mathrm{H}), 3.74(\mathrm{~s}, 1 \mathrm{H}), 3.31(\mathrm{~s}, 1 \mathrm{H}), 2.49-2.36(\mathrm{~m}, 2 \mathrm{H}), 2.25(\mathrm{~S}, 3 \mathrm{H})$

${ }^{13} \mathrm{C}$ NMR $\left(100 \mathrm{MHz}, \mathrm{CDCl}_{3}\right): \delta 188.51,130.59,129.56,127.63,127.44,126.73,121.50$, 83.63, 72.60, 39.22, 35.61, 29.09, 21.31; IR $\mathrm{CH}_{2} \mathrm{Cl}_{2} \max / \mathrm{cm}^{-1}: 3257(\mathrm{~N}-\mathrm{H}), 2957,2931$ (aromatics), 1519, 1179, 1038, 752; HRMS $m / z$ found 505.1954 $\mathrm{C}_{27} \mathrm{H}_{34} \mathrm{O}_{2} \mathrm{~N}_{2} \mathrm{~S}_{2}\left(\mathrm{M}^{+} \mathrm{Na}\right)$ expected $505.1954\left(\mathrm{M}^{+} \mathrm{Na}\right)$; Elemental analysis found $\mathrm{C} 66.96 ; \mathrm{H} 7.02 ; \mathrm{N} 5.73 \%$ $\mathrm{C}_{25} \mathrm{H}_{23} \mathrm{NO}_{2} \mathrm{~S}$ requires C 67.18; H 7.10; N $5.80 \%$.

\section{X-ray Crystallography}

Diffraction data for $( \pm)-\mathbf{1 0 a} \cdot \mathbf{C H C l}_{3}$ and $( \pm)-\mathbf{1 0 b} \cdot \mathbf{M e O H} \cdot \mathbf{C H}_{3} \mathbf{C N}$, and were collected on a Bruker APEX 2 CCD diffractometer equipped with graphite-monochromated Mo-Ka Xradiation. Diffraction data for $(+)-\mathbf{1 0 b},( \pm)-\mathbf{1 0 c} \cdot \mathbf{0 . 2 5} \mathrm{C}_{5} \mathrm{H}_{12}$, and $( \pm)-\mathbf{1 0 d}$ and were collected on 
a Bruker APEX 2 CCD diffractometer equipped with a silicon 111 monochromator using narrow frame $\omega$-scans on Station 11.3.1 at the ALS using synchrotron radiation. ${ }^{38}$ Data for ( \pm -10e were also collected at the ALS but with a Bruker D8 diffractometer with a CMOS detector using shutterless $\omega$-scans. Data were corrected for absorption and Lp effects. ${ }^{38}$ Structures were solved by direct methods or charge flipping algorithms ${ }^{39,40}$ and refined by full-matrix least squares on $F^{2}{ }^{41}$ Further details are given in Table 7 in the ESI. In ( \pm )$10 \mathrm{a} \cdot \mathbf{C H C l}_{3}$ the $\mathrm{CHCl}_{3}$ molecule was modeled as disordered over two sets of positions with major component $63.6(6) \%$. In $( \pm)-\mathbf{1 0 b} \cdot \mathbf{M e O H} \cdot \mathbf{C H}_{3} \mathbf{C N}$ the $\mathrm{MeOH}$ molecule is disordered over a 2-fold axis and the $\mathrm{OH}$ position could not be reliably determined, so was not refined. In $( \pm)-\mathbf{1 0} \cdot \mathbf{0 . 2 5} \mathbf{C}_{5} \mathbf{H}_{12}$ there are two cleft molecules in the asymmetric unit, both exhibiting disorder. $\mathrm{CF}_{3}$ groups at $\mathrm{C}(26), \mathrm{C}(34), \mathrm{C}(35), \mathrm{C}(69)$ and $\mathrm{C}(70)$ were all modeled as two-fold disordered, as were the ring atoms $\mathrm{C}(54)>\mathrm{C}(57)$ and the $\mathrm{CF}_{3}$ group at $\mathrm{C}(60)$. The badly disordered partial pentane of crystallization was modeled as a diffuse area of electron density by the Platon Squeeze procedure. ${ }^{42}$ The structure of $( \pm)-10 e$ is presented as provisional due to the severe crystallographic problems encountered associated with space group ambiguity. Data sets were collected both in the home laboratory and at the ALS synchrotron. In both cases the same unit cell parameters were obtained. Crystal data for $( \pm)-\mathbf{1 0 e}: \mathrm{C}_{27} \mathrm{H}_{34} \mathrm{~N}_{2} \mathrm{O}_{2} \mathrm{~S} 2$, $M=482.68$, monoclinic, $P c\left(\right.$ or $\left.P 2{ }_{1} / c\right), a=12.2150(11), b=26.553(2), c=24.029(2) \AA, \beta=$ $99.357(5)^{\circ}, V=7690.0(11) \AA^{3}, Z=12, \mu=0.234 \mathrm{~mm}^{-1}, 77800$ reflections measured, 25961 unique, $R_{\text {int }}=0.0749, R_{1}\left[F^{2}>2 \sigma\left(F^{2}\right)\right]=0.2110$. Similarity restraints were applied to the geometry of all molecules and global restraints were required for anisotropic displacement parameters. Six molecules in the asymmetric unit in two groups of three for space group $P c$, which gave the best result (one group of three in space group $P 2_{1} / c$ ). $\mathrm{N}-\mathrm{H} \cdots \mathrm{S}$ H-bonds in the range $3.28(2)-3.541(13) \AA$ and $\mathrm{C}-\mathrm{H} \cdots \pi$ distances in the range $2.41-2.75 \AA$.

\section{ASSOCIATED CONTENT}




\section{Supporting Information}

The Supporting Information is available free of charge on the ACS Publications website. Experimental procedures for the synthesis of $(+)-9,(-)-9,( \pm)-9$, as well as the HPLC traces of (+)-9, (-)-9 and ( \pm )-9. Spectroscopic data for all reported compounds. Table S1 contains the crystallographic data for $( \pm)-\mathbf{1 0 a},(+)-10 b,( \pm)-10 b,( \pm)-10 c$ and $( \pm)-10 d$. Tables S2-S7 contain selected H-bonded geometries for $( \pm)-\mathbf{1 0 a},(+)-\mathbf{1 0 b},( \pm)-\mathbf{1 0 b},( \pm)-\mathbf{1 0 c}$ and $( \pm)-\mathbf{1 0 d}$, respectively. Figures S1-S6 contains ORTEP plots of $( \pm)-\mathbf{1 0 a},(+)-\mathbf{1 0 b},( \pm)-\mathbf{1 0 b},( \pm)-\mathbf{1 0 c}$ and $( \pm)-10 d$ (two molecules), respectively. Figure S7 depicts the H-bonding network of $( \pm)-\mathbf{1 0 c}$, and Figure S8 the H-bonding network of $( \pm)-\mathbf{1 0 e}$.

\section{Accession Codes}

CCDC 1441482-1441486 contains the supplementary crystallographic data for this paper. These data can be obtained free of charge from The Cambridge Crystallographic Data Centre via www.ccdc.cam.ac.uk/data_request/cif, or by emailing data_request@eccdc.cam.ac.uk, or by contacting The Cambridge Crystallographic Data Centre, 12, Union Road, Cambridge CB2 1EZ, UK; fax: +44 1223336033.

\section{AUTHOR INFORMATION}

\section{Corresponding Authors}

Email: M.C.Kimber@lboro.ac.uk, Tel. +44 (0) 1509222570

Email: M.R.J.Elesgood@lboro.ac.uk Tel. +44 (0) 1509228751

\section{Notes}

The authors declare no competing financial interests.

\section{ACKNOWLEDGMENT}


We gratefully acknowledge financial support from Loughborough University (studentship for NHS). We also thank Dr. Mark Edgar (Loughborough) for assistance with NMR assignments. The Advanced Light Source is supported by the Director, Office of Science, Office of Basic Energy Sciences, of the U.S. Department of Energy under Contract No. DEAC02-05CH11231.

\section{REFERENCES}

1. Stetter, H.; Reischl, A. Chem. Ber. 1960, 93, 791.

2. Tatemitsu, H.; Ogura, F.; Nakagawa,Y.; Nakagawa, M.; Naemura, K.; Nakagawa, M. Bull. Chem. Soc. Jpn. 1975, 48, 2473.

3. For a review, see: Turner, J. J.; Harding, M. M. Supramol. Chem. 2005, 17, 369.

4. Friberg, A.; Olsson, C.; Ek, F.; Berg, U.; Frejd, T. Tetrahedron: Asymmetry 2007, 18, 885.

5. Field, J. D.; Turner, P.; Harding, M. M.; Hatzikominos, T.; Kim, L. New J. Chem. 2002, 26, 720 .

6. Anderberg, P. I.; Turner, J. J.; Evans, K. J.; Hutchins, L. M.; Harding, M. M. J. Chem. Soc., Dalton Trans. 2004, 1708.

7. Lee, C. K. Y.; Groneman, J. L.; Turner, P.; Rendina, L. M.; Harding, M. M. Tetrahedron 2006, 62, 4870 .

8. Naemura, K.; Fukunaga, R. Chem. Letts. 1985, 1651.

9. Naemura, K.; Fukunaga, R.; Yamanaka, M. J. Chem. Soc., Chem. Commun. 1985, 1560. 
10. Naemura, K.; Fukunaga, R.; Komatsu, M.; Yamanaka, M.; Chikamatsu, H. Bull. Chem. Soc. Jpn. 1989, 62, 83.

11. Thunberg, L.; Allenmark, S.; Friberg, A.; Ek, F.; Frejd, T. Chirality 2004, 16, 614.

12. Try, A. C.; Painter, L.; Harding, M. M. Tetrahedron Lett. 1998, 39, 9809.

13. Kimber, M. C.; Try, A. C.; Painter, L.; Harding, M. M.; Turner, P. J. Org. Chem. 2000, 65, 3042.

14. Jilka, P.; Millington, C.; Elsegood, M. R. J.; Frese, J. W. A.; Teat, S.; Kimber, M. C. Tetrahedron 2010, 66, 9327.

15. Elsegood, M. R. J.; Kimber. M. C. Tetrahedron Lett. 2015, 56, 346.

16. For recent reviews in the area of crystal engineering see Mukherjee, A. Cryst. Growth Des. 2015, 15, 3076.

17. Desiraju, G. R. J. Am. Chem. Soc. 2013, 135, 9952.

18. Christer B. Aakeröy, C. B.; Champness, N. R.; Janiak, C. CrystEngComm. 2010, 12, 22.

19. Mann, S. Nature 1993, 365, 499.

20. Hosseini, M. W. CrystEngComm. 2004, 6, 318.

21. Hosseini, M. W.; De Cian, A. Chem. Commun. 1998, 727.

22. Hossieni, M. W. Acc. Chem. Res. 2005, 38, 313.

23. Tröger, J. J. Prakt. Chem. 1887, 36, 225.

24. Rúnarsson, Ö. V.; Artacho, J.; Wärnmark, K. Eur. J. Org. Chem. 2012, 7015. 
25. Cross, J. T.; Rossi, N. A.; Serafin, M; Wheeler, K. A. CrystEngComm. 2014, 16, 7251

26. Etter, M. C. Acc. Chem. Res. 1990, 23, 120.

27. Bernstein, J.; Davis, R. E.; Shimoni, L.; Chang, N. -L. Angew. Chem., Int. Ed. Engl. $1995,34,1555$.

28. ORTEP plots of compound $( \pm)-\mathbf{1 0 a}-\mathbf{e}$ and $(+)-\mathbf{1 0 b}$ can be found with in the Supporting information.

29. See table S1 with the Supporting Information.

30. Due to small crystal dimensions this data set was collected using synchrotron radiation at the ALS.

31. See table S2 with the Supporting Information.

32. See table S3 with the Supporting Information.

33. Modeled with atoms $\mathrm{C}(54)>C(57), C(60)$ and $F(13)>F(15)$

34. See table S4 with the Supporting Information.

35. See table S5 with the Supporting Information for the geometry of the C-H... $\mathrm{H}$-bond interactions between stacked molecules of $( \pm)-\mathbf{1 0 d}$.

36. See table S6 with the Supporting Information.

37. See figure S7 within the Supporting information.

38. APEX 2 and SAINT (2012) software for CCD diffractometers. Bruker AXS Inc., Madison, USA. 
39. Sheldrick, G. M., Acta Crystallogr. 2008, A64, 112.

40. Sheldrick, G. M., Acta Crystallogr. 2015, A71, 3.

41. Sheldrick, G. M., Acta Crystallogr. 2015, C71, 3.

42. Spek, A. L., Acta Crystallogr. 1990, A46, C34. 
For table of Contents Use Only

Controlling the assembly of C2-symmetric molecular tectons using a thiocarbamate appended carbocyclic cleft molecule analogous to Tröger's base

Natasha H. Slater, ${ }^{a}$ Benjamin R. Buckley, ${ }^{a}$ Mark R. J. Elsegood, ${ }^{a^{*}}$ Simon J. Teat ${ }^{b}$ and Marc

C. Kimber ${ }^{a^{*}}$

${ }^{a}$ Department of Chemistry, Loughborough University, LE11 3TU, UK.

${ }^{b}$ ALS, Berkeley Laboratory, 1 Cyclotron Road, MS2-400, Berkeley, California, 94720, USA
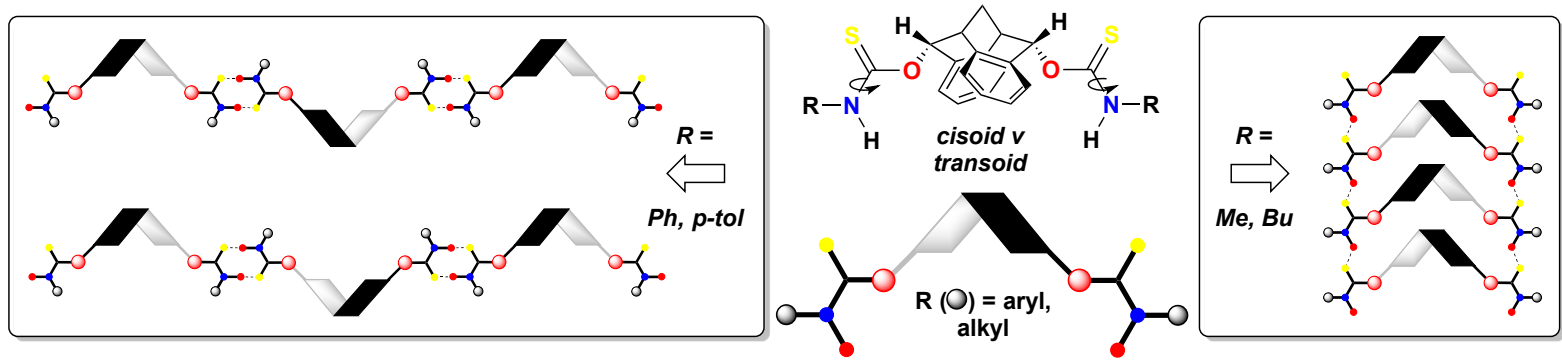

By appending the $\mathrm{C}_{2}$-symmetric carbocyclic cleft diol, an analogue of Trögers base, with thiocarbamates with varying substituents (both alkyl and aryl) gives significant control of the H-bonded network. This leads to unique solid-state structures that have been fully characterized by crystallographic analysis. Additionally, a new type of intermolecular stacking interaction of the carbocyclic cleft molecules (M5), has been observed. 